\title{
TRADISI SAPARAN \\ DALAM BUDAYA MASYARAKAT JAWA \\ DI LUMAJANG
}

\author{
Tutuk Ningsih \\ Institut Agama Islam Negeri Purwokerto \\ Jl. A. Yani 40-A (+62-281)-635624 Purwokerto 53126 \\ E-mail: tutuk@iainpurwokerto.ac.id
}

A bstrak: Indonesia has diverse tribes and traditions that make Indonesia rich of various cultures. As an ancestral heritage, cultural traditions are still preserved by Indonesian society. There are some traditions that are carried out every year, as well as by Javanese who continue to enforce their cultural traditions, because it relates to their religion and does not harm the society. This study aims to describe and analyze Saparan Tradition of J avanese society. This research implements qualitative research method, with the data is obtained directly from the field through observation at the actual conditions in the society, among Moslem Javanese. The data collections in this study are observation, documentation and interview. The results of the study related to the socio-cultural and religious conditions of Ditotrunan society. They are unique. Geographically, their location is in the center of the city, but still holding the tradition of saparan every year. The tradition on Safar Month, which is known as saparan by the Javanese in Lumajang, is carried out by making jenang as an expression of gratitude or slametan. Each family makes jenang in Safar $M$ onth, they take turns to make jenang, and then it is served in a leafcoated plate. After everything is ready, it will be presented on the table. Then, the head of the household leads a prayer for goodness, then sharing jenang to the neighbors and the relatives next to them. In addition, in saparan tradition, there is also a festival followed by ladies dressed in kebaya (J avanese B louse), they work together to make jenang. A fter cooking, they place the meal on a grounded leaf plate. Then, a prayer is conducted and led by the priest. Finally, they eat jenang together in the society.

Keywords: Saparan Tradition and J avanese Culture 


\section{Ibda' Jurnal Kajian Islam dan Budaya}

A bstrak: Bangsa Indonesia memiliki suku bangsa dan adat istiadat yang beraneka ragam sehingga membuat bangsa Indonesia kaya dengan berbagai kebudayaan. Sebagai warisan nenek moyang, tradisi kebudayaan yang ada tetap dilestarikan oleh masyarakat, bahkan ada beberapa tradisi yang dilaksanakan setiap tahunnya, seperti halnya oleh masyarakat Jawa yang terus melaksanakan tradisi budayanya karena memiliki kaitan dengan agama dan tidak merugikan masyarakat. Penelitian ini bertujuan untuk mendeskripsikan dan menganalisa tradisi saparan dalam budaya masyarakat Jawa. Penelitian ini menggunakan metode penelitian kualitatif, dengan data yang diperoleh secara langsung dari lapangan melalui melihat kondisi yang sebenarnya di lapangan yaitu di tengah-tengah masyarakat Jawa yang bergama Islam. Pengumpulan data dalam penelitian ini meliputi, observasi, dokumentasi, dan wawancara. Hasil penelitian terkait keadaan sosial budaya dan keagamaan masyarakat desa Ditotrunan dengan keunikan yang dimiliki desa ini yaitu, letak geografis desa yang berada di pusat kota, namun masih mengadakan tradisi saparan setiap tahun, yaitu di bulan safar. Tradisi di bulan sapar yang namanya terkenal dengan sebutan saparan oleh masyarakat Jawa di daerah Lumajang ini dilaksanakan dengan membuat jenang sapar sebagai bentuk syukur atau slametan. Setiap rumah membuat jenang sapar di bulan sapar, mereka bergantian membuat jenang tersebut, dan setelah selesai disajikan dalam piring berlapis daun, setelah semua tersaji di atas meja, kemudian kepala rumah tangga memimpin doa untuk kebaikan, dilanjutkan berbagi jenang saparan ke tetangga dan kerabat yang dekat. Selain itu dalam pelaksanan saparan diadakkan pula suatu festival yang diikuti Ibu-lbu berpakaian kain kebaya, mereka bekerjasama membuat jenang sapar, setelah masak di taruh dipiring beralasan daun, kemudian dilaksanakan doa bersama yang dipimpin oleh kyai, setelah itu mereka makan jenang sapar bersama seluruh elemen masyarakat.

$\mathrm{K}$ ata kunci: tradisi saparan dan budaya masyarakat Jawa

\section{A. Pendahuluan}

$M$ asyarakat J awa mempunyai kebudayaan yang sangat tinggi, hal itu didukung dengan sumber daya manusia yang sangat baik dan juga dukungan sumber daya al am yang sangat melimpah. Pandangan hidup orang J awa sel alu mengedepankan keselamatan di dunia dan akhirat dengan menggunakan situasi dan kondisi yang ada pada lingkungan sekitarnya. Pandangan tentang dunia akhirat itu dapat kita lihat dalam perkembangan spiritual yang ada di 
Jawa, salah satu contoh dari hal itu adalah adanya kepercayaan-kepercayaan masyarakat J awa terhadap energi-energi yang berasal dari lingkungannya yang mempunyai daya magis baik secara animisme maupun dinamisme. Kepercayaan yang sudah ada di Jawa sejak berabad-abad tersebut secara langsung mempengaruhi pola kehidupan dan pandangan masyarakat yang ada di Jawa (Hemawan, 2014: 46).

Tradisi dan budaya J awa ti dak hanya memberikan warna dal am peraturan kenegaraan, tetapi juga berpengaruh dalam keyakinan dan praktik-praktik keagamaan. M asyarakat J awa memiliki tradisi dan budaya yang banyak, meskipun mereka sudah memiliki keyakinan atau agama yang berbeda, seperti Islam, K risten, atau lainnya yang dipengaruhi ajaran dan kepercayaan Hindhu dan Budha, masih terus bertahan hingga sekarang. Tradisi dan kebudayan sebagai hasil dari cipta, rasa, dan karsa manusia merupakan suatu keseluruhan yang kompleks dari unsur-unsur yang berbeda-beda seperti pengetahuan, kepercayaan, seni, hukum, moral, adat istiadat, dan segala kecakapan yang diperoleh manusia sebagai anggota masyarakat ( $M$ asrin, 2009: 2).

Budaya yang dilaksanakan oleh masyarakat L umajang di bulan sapar sebagai peninggalan nenek moyang yaitu tradisi membuat jenang sapar di bulan sapar, tujuannya pembuatan jenang sapar ini sebagai perekat hubungan masyarakat kekerabatan warisan walisongo, yaitu sebagai pancaran atau pengejawentahan budi manusia J awa yang mencakup kemauan, cita-cita, ide maupun semangat untuk mencapai kesejahteraan, keselamatan dan kebahagiaan hidup lahir batin (Partokusumo, 1995: 166)

Tradisi saparan tersebut dilaksanakan setiap tahun dan sekarang tradisi tersebut dibudayakan dan dijadikan acara festival saparan yang diikuti seluruh warga masyarakat desa Ditotrunan oleh karena itu peneliti tertarik ingin meneliti di desa Ditotrunan karena mayoritas agama masyrakat desa tersebut Islam dan masih merayakan tradisi tradisi jawa terutama saparan. B erdasarkan uraian di atas, penulis tertarik meneliti tentang tradisi saparan dalam budaya masyarakat J awa di desa Ditotrunan kecamatan L umajang kabupaten Lumajang J awa Timur.

Tradisi saparan tersebut dilaksanakan setiap tahun dan sekarang tradisi tersebut di budayakan dan dijadikan acara festival saparan yang diikuti seluruh warga masyarakat desa Ditotrunan oleh karena itu peneliti tertarik ingin meneliti di desa D itotrunan karena mayoritas agama masyrakat desa tersebut 


\section{Ibda' Jurnal Kajian Islam dan Budaya}

Islam dan masih merayakan tradisi tradisi jawa terutama saparan. B erdasarkan uraian di atas, penulis tertarik meneliti tentang tradisi saparan dalam budaya masyarakat Jawa di desa Ditotrunan kecamatan Lumajang kabupaten Lumajang J awa Timur.

\section{B. TEORI}

Tradisi dalam kamus A ntropologi sama dengan adat istiadat yakni kebiasaan-kebiasaan yang bersifat magis-religius dari kehidupan suatu penduduk asli yang meliputi mengenai nilai-nilai budaya, norma-norma, hukum dan aturan-aturan yang saling berkaitan, dan kemudian menjadi suatu sistem atau peraturan yang sudah mantap serta mencakup segala konsepsi sistem budaya dari suatu kebudayaan untuk mengatur tindakan sosial (A rriyono dan A minuddin Siregar, 1985: 4). A dapun dalam kamus sosiologi, diartikan sebagai adat istiadat dan kepercayaan yang secara turun temurun dapat dipelihara (Soekanto: 459).

Tradisi adalah kebiasaan-kebiasaan yang turun-menurun sekelompok masyarakat berdasarkan nilai budaya masyarakat yang bersangkutan. Tradisi memperlihatkan bagaiman anggota masyarakat bertingkah laku, baik dalam kehidupan yang bersifat gaib atau keagamaan (Esten, 1992: 14). Dalam konteks keilmuan A rab, tradisi biasa disebut turats, yang berarti segala warisan masa lampau yang masuk ke dalam kebudayaan yang sekarang berlaku. Turats tidak hanya peninggalan sejarah, tetapi sekaligus merupakan kontribusi zaman sekarang dalam berbagai bentuk dan tingkatannya (Hakim, 2003: 29).

Dalam definisi yang lain, tradisi adalah segala sesuatu yang disalurkan atau diwariskan dari masa lalu kemasa kini. Dalam pengertian yang lebih sempit tradisi hanya berarti bagian-bagian warisan sosial khusus yang memenuhi syarat saja yakni yang tetap bertahan hidup di masa kini. Tradisi adalah kesamaan benda material dan gagasan yang berasal dari masa lalu namun masih ada hingga kini dan belum dihancurkan atau dirusak. Tradisi dapat diartikan sebagai warisan yang benar atau warisan masa lalu. Namun demikian tradisi yang terjadi berulang-ulang bukanlah dilakukan secara kebetulan atau disengaja (Piotr Sztompka, 2007: 70).

Dari berbagai definisi diatas dapat disimpulkan bahwa tradisi adalah warisan masa lalu yang hidup dan diwariskan ditengah-tengah masyarakat yang berisi seperangkat ide dan pandangan ideal cita-cita bersama, serta 
memuat berbagai aturan tentang idealitas dalam menjalani kehidupan bersama ditengah masyarakat.

Dalam tradisi diatur bagaimana konsep hubungan manusia dengan manusia yang lain dalam suatu kelompok, kelompok manusia dengan kelompok yang lain atau hubungan manusia dengan alam lingkunganya. Konsep inilah yang kemudian berkembang menjadi suatu sistem dan memiliki pola yang sekaligus juga mengatur penggunaan sanksi dan ancaman terhadap pelanggaran dan penyimpangan.

Sebagai sistem budaya tradisi juga merupakan suatu sistem yang menyeluruh, yang terdiri dari cara yang memberikan arti ujaran, laku ritual dan berbagai laku lainya dari manusia dalam berhubungan dengan sesama manusia atau yang lainya, dimana unsur terkecil dari sistem ini adalah simbol yang meliputi simbol konstitutif (yang berbentuk kepercayaan), simbol kognitif (yang berbentuk pengetahuan), simbol penilaian norma, dan sistem ekspresif, atau simbol yang menyangkut pengungkapan perasaan (M ursal Esten, 1999: 22).

Tradisi sebagai warisan yang hidup ditengah-tengah masyarakat muncul melalui dua cara, pertama, muncul dari bawah melalui mekanisme kemunculan secara spontan dan tak diharapkan serta melibatkan rakyat banyak. $\mathrm{K}$ arena sesuatu alasan, individu tertentu menemukan warisan historis yang menarik perhatian, kecintaan dan kekaguman yang kemudian disebarkan melalui berbagai cara mempengaruhi rakyat banyak. Sikap-sikap tersebut berubah menjadi perilaku dalam bentuk upacara, penelitian dan pemugaran peninggalan purbakala serta menafsir ulang keyakinan lama.

$K$ Kedua, tradisi muncul dari atas melalui mekanisme paksaan. Sesuatu yang dianggap tradisi dipilih dan dijadikan perhatian umum atau dipaksakan oleh individu yang berpengaruh atau berkuasa. Dua jalan kelahiran tradisi tersebut tidak membedakan kadarnya. Perbedaannya terdapat antara "tradisi asli", yakni yang sudah ada di masa lalu. Tradisi buatan mungkin lahir ketika orang memahami impian masa lalu dan mampu menularkan impian itu kepada orang banyak. Lebih sering tradisi buatan ini dipaksakan dari atas oleh penguasa untuk mencapai tujuan politik mereka.

Dalam konteks hubungan manusia dengan tradisi itu sendiri, terjadi relasi dimana manusia tak mampu hidup tanpa tradisi meski mereka sering merasa tak puas terhadap tradisi mereka (Piotr Sztompka, 2007: 74). Tradisi bagi 


\section{Ibdg' Jurnal Kajian Islam dan Budaya}

masyarakat memiliki empat fungsi antara lain:

1. Tradisi sebagai kebijakan turun-temurun, menyediakan fragmen historis yang kita pandang bermanfaat, seperti onggokan gagasan dan material yang digunakan dalam tindakan masa kini dan untuk membangun masa depan.

2. Tradisi merupakan sumber legitimasi bagi pandangan hidup, keyakinan, pranata dan aturan yang sudah ada.

3. M enyediakan simbol identitas kolektif yang meyakinkan, memperkuat loyalitas primordial terhadap bangsa, komunitas dan kelompok.

4. M embantu menyediakan tempat pelarian dari keluhan, kekecewaan dan ketidakpuasan kehidupan modern. Tradisi yang mengesankan masa lalu yang lebih bahagia menyediakan sumber pengganti kebanggaan bila masyarakat berada dalam krisis (Sztompka, 2007: 75-76).

Tradisi dapat dibagi dalam beberapa level. Pertama, tradisi dapat ditemukan dalam bentuk tulisan berupa bukubuku atau lainnya yang tersimpan di berbagai perpustakaan atau tempat-tempat lain. K edua, tradisi juga bisa berupa-konsep-konsep, pemikiran, dan atau ide-ide yang masih hidup dan hadir di tengah realitas (Wasid, 2011: 31). Dua sisi yang berbeda, yang pertama bersifat material dan kedua bersifat abstrak. $N$ amun keduanya tidak dapat dipisahkan dari realitas, karena setiap tradisi telah mengusung semangat zamannya, mencerminkan tahap perjalanan sejarah.

\section{Pembahasan}

Saparan merupakan sebuah tradisi Jawa yang dilaksanakan ol eh masyarakat, baik di J awa Timur maupun J awa Tengah, akan tetapi setiap daerah memiliki ciri khas tersendiri dan prosesnya berbeda. Bulan Sapar menurut penanggal an I slam merupakan bulan kedua dal am kalender hijriyah. Tidak ada amalan ibadah khusus yang dicontohkan oleh Rasulullah SAW di bulan ini, sebagaimana di bulan-bulan lain. Hanya saja, bulan ini menurut anggapan masyarakat memiliki karakteristik yang sangat unik dan sarat dengan mitos. Banyak tradisi atau kepercayaan nenek moyang yang sampai saat sekarang masih dipertahankan dan dilestarikan dan dikaitkan dengan beberapa peristiwa yang muncul dibulan ini (Widodo, dkk., 2015: 74). 


\section{Keadaan Sosial Budaya dan Keagamaan Masyarakat Desa Ditotrunan}

K abupaten L umajang merupakan salah satu daerah yang berada di wilayah bagian selatan Propinsi J awa T imur. K abupaten L umajang terdiri dari 21 kecamatan dengan batas-batas wilayah yaitu sebelah utara kabupaten Probolinggo, sebelah timur kabupaten J ember, sebelah selatan Samudera Indonesia, dan sebelah barat kabupaten $\mathrm{M}$ alang.

Sebagaimana pada umumnya kabupaten yang berada di daerah selatan, maka kabupaten L umajang memiliki potensi yang cukup besar pada sektor pertanian dan pertambangan meskipun bel um sepenuhnya dapat dieksploitasi secara optimal. M eskipun peningkatan paling besar berikutnya adalah pada sektor sekunder dan tersier, namun hal itu menunjukkan bahwa sektor tersebut mengalami imbas kenaikan karena disebabkan sektor primer yang semakin berkembang

Ditotrunan terletak di kecamatan L umajang kota kabupaten L umajang, tepatnya terletak di belakang rumah jabatan bupati L umajang sehingga desa Ditotrunan masih termasuk daerah perkotaan, ol eh karenanya keunikan desa ini adalah letaknya di pusat kota tetapi masih mengadakan tradisi saparan. $M$ asyarakat Lumajang mayoritas beragama Islam, masjid yang ada di kecamatan ini merupakan masjid yang paling besar dan terletak di sekitar alunal un kabupaten L umajang. M asyarakat L umajang memiliki tingkat religius yang tinggi, hal ini dapat dilihat saat sholat lima waktu maupun sholat J umat dengan jamaah yang banyak, apalagi saat bulan Romadhon banyak jamaah yang sholat tarawih di masjid J ami' begitu juga pada hari raya idul adha dan idul fitri masjid tersebut penuh sampai ke alun-alun kabupaten L umajang. Tokoh agama di kabupaten L umajang sangat berperan sekali terutama yang beragama Islam, selain sebagai tokoh agama mereka sebagai guru agama di sekolah-sekolah negeri dan swasta, dan kerjasama antara golongan agama sangat rukun terutama dalam peringatan hari hari besar Islam di kabupaten Lumajang.

K eberagaman agama pada masyarakat desa Ditotrunan ditunjukan dengan adanya gereja-gereja $\mathrm{K}$ atolik sebagai tempat ibadah masyarakat yang sebagian besar warga China, dan sebagian lagi warga asli L umajang dan pendatang. M eskipun agama yang dianutnya berbeda, akan tetapi tingkat solidaritas masyarakat sangat tinggi, kebersamaan di desa tersebut seperti 


\section{Ibda' Jurnal Kajian Islam dan Budaya}

tidak ada perbedaan, saling hormat menghormati sehingga hidup mayarakat rukun. Secara sosiologis masyarakatnya masih seperti masyarakat pedesaan karena kabupaten L umajang terletak di bawah gunung semeru dan merupakan daerah dingin. Dilihat dari pola interaksi masyarakat dalam mengembangkan tradisi saparan dengan pola yang dilaksanakan setiap tahun, maka masyarakat desa Ditotrunan merupakan masyarakat yang memiliki kesadaran tinggi untuk saling tolong-menolong, saling menghargai, bertoleransi, dan rukun. K ebersamaan masyarakat sangat kuat untuk memajukan kota L umajang yang asri dan bersih, sehingga kabupaten tersebut mendapatkan adipura kota terbersih di provinsi J awa Timur.

\section{Pelaksanaan Tradisi Saparan di Desa Ditotrunan}

$M$ asyarakat Ditotrunan melaksanakan tradisi yang memang sudah dilaksanakan secara turun-temurun sebagai tradisi warisan nenek moyang. Salah satunya adalah tradisi saparan sebuah tradisi yang melibatkan semua warga desa Ditotrunan. Tradisi saparan merupakan slametan atau syukuran desa agar masyarakat mendapatkan keberkahan, kebahagian atas limpahan rejeki. Tradisi saparan ini dilaksanakan pada bulan sapar, karena bulan tersebut merupakan bulan baik menurut warga D itotrunan, seperti yang dikatakan I da warga Ditotrunan bahwa,

"setiap bulan sapar saya mengadakan slamatan di rumah membuat jenang sapar dan sebelum diantar ke rumah tetangga didoakan terlebih dahulu oleh suami saya, setelah selesai berdoa lalu diantar ke tetangga kanan-kiri, dan saudara yang terdekat."

Jenang sapar ini hanya ada di bulan sapar karena cara membuatkan agak sulit dan di pasar atau di toko kue tidak pernah ketemu dengan jenang sapar ini, oleh sebab itu masyarakat Ditotrunan tidak bosan memakan jenang ini karena hanya ada di bulan sapar.

M asyarakat Ditrotrunan yang beragam Islam melaksanakan tradisi bukan hanya saparan tetapi masih banyak lagi yang dilakukan yaitu bulan maulid $\mathrm{N}$ abi M uhammad SAW acara yang dilaksanakan yaitu mereka membawa keranjang yang dihias, isinya nasi dan lauk pauk, atau kue atau buah dibawa ke masjid, dan didoakan oleh kyai. M asyrakat bersama-sama mendengarkan pengajian dan berdoa setelah sel esai mereka pulang membawa makanan yang 
di bawa dari masjid, tetapi mengambilnya sistem acak, kegiatan bulan syuro warga membuat membuat jenang syuro. Dan hari Idul adha, idul fitri masyrakat Ditotrunan melaksanakan tradisi-tradisi budaya Islam yang sudah dilaksanakan dari turun-temurun dan merupakan tradisi dari nenek moyang masyarakat L umajang.

\section{Perayaan Tradisi Saparan}

Saparan bermula sebagai slametan atau syukuran desa, warga berharap dengan diadakannya tradisi saparan ini maka desa mereka akan mendapatkan banyak berkah dan rejeki, serta jauh dari malapetaka. B ulan Sapar menurut penanggalan I slam merupakan bulan kedua dalam kalender hijriyah. Tidak ada amalan ibadah khusus yang dicontohkan oleh Rasulullah SAW di bulan ini sebagaimana di bulan-bulan lain. Hanya saja, bulan ini menurut anggapan masyarakat awam memiliki karakteristik yang sangat unik dan sarat dengan mitos sehingga menimbulkan rasa penasaran bagi orang-orang yang belum tahu. Dengan adanya mitos tersebut, orang akan semakin mendekatkan diri kepada A Ilah SWT dan dapat meningkatkan taqwa kepada-N ya. B ahkan ada yang berpendapat bahwa setiap apa-apa yang melalaikan dan memalingkan dari A Ilah SWT adalah sial. J adi semua bulan menurut Islam adalah baik, tidak ada bulan maupun hari yang dianggap buruk karena semua itu adalah anggapan dari manusia semata, B ahkan A llah SWT dengan tegas menyebutkan bahwa bencana yang terjadi justru akibat dari perbuatan manusia itu sendiri, bukan karena hari sial atau semacamnya, seperti yang di sebutkan dal am A I-Q ur' an:

A rtinya: "D an orang-orang kafir senantiasa ditimpa bencana disebabkan perbuatan mereka sendiri atau bencana itu terjadi dekat tempat kediaman mereka sehingga datanglah janji A llah" (QS. A r-Ra'd :31)

$M$ al apetaka, bencana dan bala' menurut Islam justru dapat dicegah dengan memperbanyak amalan sedekah sebagaimana sabda R asulullah SA W:

A rtinya: Diriwayatkan dari A li ra. Dalam hadits marfu': "B ersegeralah sedekah karena bala' tidak akan melangkahinya" (HR Thabrani).

Seperti apa yang dikatakan oleh hadist tersebut umat Islam yang ada di dunia ini dianjurkan untuk banyak-banyak bersedekah, memperbanyak berdoa, menjalankan sholat wajib dan meperbanyak sholat sunnah, puasa sunnah di setiap waktu, dan diberi kesemptan yang ada tidak hanya di bulan sapar saja tetapi di bulan-bulan yang lain. Para ulama mengatakan bahwa kalau 


\section{Ibda' Jurnal Kajian Islam dan Budaya}

kita dekat dengan A llah yaitu melaksankan perintahnya dan menjauhkan larangannya maka surga dunia dan akhirat ada di tangan manusia tersebut. Dengan demikian, maka akan semakin menyadarkan manusia supaya mereka yakin bahwa semua kemujuran dan kesialan adalah sepenuhnya berada pada genggaman takdir A llah SWT dengan mendekatkan diri kepada-N ya. Oleh sebab itu saparan adalah tradisi yang dilaksanakan masyrakat supaya tidak tertimpa kesialan

B anyak tradisi atau kepercayaan nenek moyang yang saat sekarang masih dipertahankan dan dilestarikan yang dikaitkan dengan beberapa peristiwa yang muncul di bulan ini (Ida Zahara A dibah, 2015: 150) M enurut K oentjaraningrat, upacara-upacara slametan yang dilakukan oleh masyarakat Jawa diyakini untuk menangkal pengaruh buruk yang bisa mengancam keberlangsungan hidupnya (K oentjaraningrat, 1994: 4). Sehingga masyarakat desa Ditotrunan mengadakan tradisi saparan dari tahun ke tahun supaya terhindar dari malapetaka, menurut keyakinan mereka bentuk slametan yang dilaksanakan oleh masyarakat desa D itotrunan dengan mengadakan slametan di bulan-bulan Jawa seperti tradisi saparan.

Tradisi saparan sebagai sebuah tradisi yang dilaksanakan masyarakat J awa dan hampir melibatkan semua masyarakat yang ada. M asyarakat J awa biasa melaksankan tradisi sesuai dengan penanggalan J awa dalam kal ender jawa, begitu pula tradisi saparan pun dilaksnakan oleh masyarakat pada bulan sapar sesuai dengan hari pasaran dalam kalender J awa. Tradisi di bulan sapar yang namanya terkenal dengan saparan, diisi oleh masyarakat J awa di daerah L umajang dengan membuat jenang sapar sebagai slametan untuk syukuran akan datang bulan sapar seperti yang diungkapkan oleh Tuti bahwa:

"membuat jenang sapar itu warisan dari turun-temurun, atau dari nenek moyang yang berasal dari daerah L umjang, kegiatan ini dilakukan tiap tahun, setiap rumah membuat jenang sapar di bulan sapar, mereka bergantian membuat jenang tersebut, dan setelah selesai membuat jenang dan ditaruh di piring yang dialasi daun, setelah semua tersaji di atas meja didoakan oleh kepala rumah tangga, dan diantarkan ke tetangga kanan kiri dan kerabat yang dekat".

Dalam tradisi saparan ini masyarakat saling berbagi jenang selama bulan sapar, warga membuat jenang sapar untuk dikonsumsi sendiri sekaligus membagikannya kepada tetangga dan saudara dekatnya, sebagaimana penuturan Ibu Ratna bahwa, 
"bulan sapar itu kita hampir seminggu makan jenang sapar karena setiap warga yang mampu ekonominya membuat jenang sapar dan diantarkan ke tetangga kiri kanan dan saudara terdekat jadi kadang-kadang sampai bosan."

Sekilas apabila dilihat dari sudut pandang ekonomi, tradisi saparan ini merupakan pemborosan, akan tetapi tujuan dari kegiatan ini adalah untuk mencari keberkahan dan keselamatan dunia akhirat. Dalam tradisi saparan ini pun tidak lepas dengan adanya doa-doa, dan juga tetap menjalankan ibadah sholat, puasa, dan perintah A Ilah SW T Iainnya supaya mendapatkan keberkahannya. J enang sapar sendiri sebagai bentuk slamaten untuk mensyukuri rezeki yang didapatkan selama setahun yang telah dikaruniakan Allah SWT. Di sisi yang lain, tradisi saparan ini merupakan warisan nenek moyang untuk mempererat kekeluargaan baik itu di keluarga maupun masyarakat.

Hal istimewa dalam tradisi saparan yang dilaksanakan di kabupaten Lumajang adalah kegiatan para ibu yang membuat jenang sapar secara bersama-sama, tepatnya di gang $\mathrm{N}$ gadiyem di desa Ditotrunan. K urang lebih sekitar seratus orang ibu rumah tangga, dengan memakai pakaian adat kebaya J awa, mereka mengikuti festival saparan untuk membuat jenang sapar secara bersama-sama. Dalam festival tersebut mereka bersama-sama membuat racikan jenang sapar dengan diawali mengucap basmallah secara serentak kemudian dilanjutkan dengan membuat bola-bola kecil yang terbuat dari tepung ketan yang sudah disediakan oleh panitia, setelah menghasilkan banyak bola-bola kecil yang terbuat dari tepung ketan, tahap selanjutnya dimasukkan ke dalam santan yang telah dicampur dengan gula J awa, gula putih, pandan, sedikit garam, kemudian dididihkan, setelah mendidih barulah kemudian bola-bola kecil tersebut ditambahkan dan diaduk sampai masak. Setelah itu mereka mendidihkan santan yang kental (kanil) untuk membuat jenang putih yang terdiri dari santan dan tepung beras dengan sedikit garam untuk kemudian dijadikan taburan di atas jenang. Setelah selesai memasak, mereka mempersiapkan wadah untuk wadah jenang yang dinamakan takir dengan menggunakan takir dari daun pisang dan untuk membuat takir ujung daun dilipat dan ujung ditemukan diberi lidi akhirnya berbentuk kotak sehingga jenang yang ditaruh didalamnya menambah keharuman jenang. M akna takir dalam Islam adalah adalah takwa dan zikir. A dalah sebagai amalan-amalan masyarakat dalam kehidupan sehari-hari baik itu bertakwa kepada A IIh SWT dan zikir merupakan amalan yang dilakukan manusia yang 


\section{Ibda' Jurnal Kajian Islam dan Budaya}

benar-benar dilaksanakan mulai dari subuh dan kembali ke subuh lagi, dalam hal amalan tersebut tidak lepas dari kehidupan masyarakat yang sebagai makhluk A llah SWT mengikuti anjuran-N ya meninggal kan larangan- $N$ ya dan makna takir itu melambangkan kesederhanaan karena dengan sebungkus takir orang bersodaqoh dan yang bisa bersodaqoh bukan hanya orang kaya, tetapi orang yang betul-betul orang yang bertakwa kepada A llah SWT.

$M$ asyarakat Lumajang dalam membuat jenang sapar itu adalah tradisi saparan tersebut kembali ke masa Ialu masa kesederhanaan. M akna jenang sapar yang terbuat dari ketan, gula jawa dan santen kental merupakan jenang yang manis dan gurih sehingga setelah makan jenang sapar masyarakat Lumajang dalam pergaulan sehari-hari semakin lengket dalam membina kekeluargaan di masyrakat dan semakin erat hubungan dalam berinteraksi di masyrakat sehingga permasalahan di masyrakat bisa dipikul bersama baik yang tua dan muda, dan si kaya dan si miskin, dengan adanya kegiatan saparan semakin mempererat tali silahturahmi .

K etika jenang safar telah siap dihidangkan, mereka duduk bersama, dan melakukan doa bersama yang dipimpin kyai $R$ ahman berdoa memohon kepada A Ilah SW T agar desa Ditotrunan aman dan sejahtera. Sehingga mitos yang ada di masyarakat tidak terjadi malapetaka di bulan sapar dan seperti yang dikatakan A bdul G hofar selaku lurah menjelaskan bahwa,

"diadakan festival membuat jenang sapar di desa Ditrotunan supaya tradisi saparan tidak punah karena ini tradisi dari nenek moyang yang selalu diadakan setiap tahun, tujuannya untuk memperat tali silahturahmi, dan menyatukan warga desa Ditrotrunan sebagai perekat kekerabatan warisan walisongo sebagai tradisi yang berjalan secara turun-temurun"

Oleh sebab itu, warga desa tidak lupa memanjatkan puji syukur melalui berdoa bersama dan meminta supaya daerah L umajang sekitarnya tidak terkena banjir yang selalu dikirim oleh gunung semeru sehingga ketakutan ketakutan warga tidak akan terjadi daerah L umajang adalah di bawah kaki gunung semeru, dan gunung tersebut sewaktu-waktu akan meletus dan membuat masyrakat ketakutan oleh sebab itu masyrakat desa Ditotrunan dengan merayakan saparan minta kesel amatan keberkahan supaya masyrakat aman dan sejahtera.

Dengan adanya doa bersama di acara tersebut tidak terlepas memohon kepada A llah SW T. B ahwa semakin banyak berdoa dan bersedekah masyarakat tersebut akan semakin didengar oleh A Ilah SW T. Sehingga 
keselamatan daerah L umajang yang sering dikirimi banjir ol eh gunung semeru tidak akan membahayakan masyarakat Lumajang.

\section{SimpUlan}

K eadaan sosial budaya dan keagamaan masyarakat desa Ditotrunan terletak di kecamatan L umajang kota kabupaten L umajang, tepatnya terl etak di belakang rumah jabatan bupati L umajang sehingga desa Ditotrunan masih termasuk daerah perkotaan, ol eh karenanya keunikan desa ini adalah letaknya di pusat kota tetapi masih mengadakan tradisi saparan. Pelaksanaan tradisi saparan yang dilaksanakan oleh warga desa Ditotrunan melibatkan semua warga sebagai bentuk slametan syukuran desa supaya mendapatkan keberkahan, kebahagian, dan kelimpahan rejeki bagi warga. U pacara slamatan atas bersukurnya kelimpahan rejeki tersebut dilaksanakan pada bulan sapar karena bulan tersebut merupakan bulan baik. Tradisi di bulan sapar yang namanya terkenal dengan saparan dilakukan oleh masyarakat J awa di daerah L umajang dengan membuat jenang sapar sebagai slametan atau syukuran untuk mensyukuri karunia rezeki selama setahun sebagai bentuk rasa sukur kepada Allah SWT.

Hal Istimewa dalam tradisi saparan yang dilaksanakan di kabupaten Lumajang, adalah kegiatan para ibu yang membuat jenang sapar secara bersama-sama, tepatnya di gang $\mathrm{N}$ gadiyem di desa Ditotrunan. K urang lebih sekitar seratus orang ibu rumah tangga, dengan memakai pakaian adat kebaya J awa, mereka mengikuti festival saparan untuk membuat jenang sapar secara bersama-sama. Dilihat dari pola interaksi masyarakat dalam mengembangkan tradisi saparan dengan pola yang dilaksanakan setiap tahun, maka masyarakat desa Ditotrunan merupakan masyarakat yang memiliki kesadaran tinggi untuk saling tolong-menolong, saling menghargai, bertoleransi, dan rukun. K eberagaman agama pada masyarakat desa Ditotrunan pun tidak menjadi hambatan untuk menjaga solidaritas masyarakat, kebersamaan di desa tersebut seperti tidak ada perbedaan, saling hormat menghormati sehingga hidup mayarakat rukun

\section{Daftar Pustaka}

A rriyono dan A minuddin Siregar. 1985. Kamus A ntropologi. Jakarta : A kademik Pressindo. 


\section{Ibda' Jurnal Kajian Islam dan Budaya}

Barker, Chris. 2002. Making Sense of Cultural Studies : Central Problems and critical Debates, London: SA GE Publications. . 2004. The SAGE Dictionary of Cultural Studies, London : SAGE Publications.

Bsj. Hamzah. T.t. Sinau Basa Jawa: Budaya Saparan (O nline) bandhongan. blogspot.com/2014/06/budaya-saparan.html diakses pada 22 September 2018.

Bustomi, Suwaji. 1986. Kebudayaan A presiasi Pendidikan Seni. Semarang: IK IP Pres.

Denzin, N. K \& Lincoln, Y. S.2009. Handbook of qualitative research (1st ed). Yogyakarta: Pustaka Pelajar.

Esten, M ural. 1992. Tradisi dan M odernitas dalam Sandiwara, Jakarta: Intermasa.

1999. K ajian Transformasi Budaya, Bandung: A ngkasa.

Hakim, Moh. Nur. 2003. "Islam Tradisional dan Reformasi Pragmatisme" A gama dalam Pemikiran Hasan Hanafi, Malang: Bayu Media Publishing.

Hemawan, Jati. Pengaruh A gama Islam terhadap K ebudayaan dan Tradisi Jawa di Kecamatan Singorojo Kabupaten Kendal. Jurnal: Dimensi, (S.I.), Vol. 2, N 0.1, November 2014.

Herusatoto. Budiono. 1987. Simbolisme dalam Budaya Jawa. Yogyakarta: $H$ anindita.

https://lumajangkab.go.id/profil/gbr_umum.php) diunduh tanggal 31, jam $14: 35$.

Jakarta: Yayasan Pustaka Obor Indonesia

K abupaten L umajang, B uku J urnal Online. ensiklopedia.ggiklan.com,id.wiki pedia. org, diskusi.biz (Online) diakses 12 N ovember 2018.

Kamajaya Partokusumo, Karkono. 1995. Kebudayaan Jawa perpaduanya dengan Islam. Yogyakarta: Ikatan Penerbit Indonesia Cabang Yogyakarta.

Kartohadikoesoemo, Soetardjo. 1984. Desa. Jakarta: B alai pustaka.

Kemendagri dalam Peraturan M enteri Dalam Negeri Nomor 56 Tahun 2015 tentang K ode dan Data Wilayah A dministrasi Pemerintahan, diunduh 29 Oktober 2018.

Koentjaraningrat. 1994. K ebudayaan Jawa. Jakarta: Balai Pustaka. 
. 2000. Pengantar ilmu antropologi. Jakarta: Rineka Cipta.

Masrin, Surya. 2009. Nilai-Nilai Pendidikan Islam dalam Tradisi Sedeka Kamapung Di Desa Peradong Kecamatan Simpang Teritip K abupaten $B$ angka $B$ arat. B angka B arat: Jurusan Tarbiyah.

Maunah, Binti. 2016. Sosiologi Pendidikan.Yogyakarta: Kalimedia.

Milles, M. B \& Huberman, A. M .. 2007. A nalisis data kualitatif. Jakarta: Universitas Indonesia Press.

M oeleong, L exy. 2005. M etodologi penelitian kualitatif. B andung: PT Remaja Rosda Karya

Nasution, S. 1988. M etode penelitian naturalistik-kualitatif. B andung: Penerbit: Tarsito.

Santana, Septiawan. 2010. M enuli IImiah M etodologi Penelitian K ualitatif. Soekanto, Kamus Sosiologi, Jakarta : PT Raja Grafindo Persada.

Sztompka, Piotr. 2007. Sosiologi Perubahan Sosial, Jakarta: Pernada M edia Grup.

Wasid, dkk. 2011. M enafsirkan Tradisi dan M odernitas; Ide-Ide Pembaharuan Islam, Surabaya: Pustaka Idea.

Widodo, Tri Widiarto, Wahyu Purwiyastuti. Makna Tradisi Saparan Bagi M asyarakat Dusun Mulungan Kelurahan Nogosaren K ecamatan Getasan K abupaten Semarang. J urnal: Widya Sari Vol. 17, N o. 2, M ei 2015: 72-79.

Zahara A dibah, Ida. Makna Tradisi Saparan di Desa Cukilan. Jurnal M adaniyah, Volume 2 Edisi IX A gustus 2015 ISSN 2086-3462. 